\title{
Better Prediction of Neuro - Developmental Outcome in Babies Using Combined Vojta's Neurokinesiological Examination, Amiel Tison Angles and Head Holding Grades
}

\author{
Ashish Jain ${ }^{1}$, H Veerabhadrappa ${ }^{2}$, SW Shrikant ${ }^{2}$ and Nisha Kumari ${ }^{3}$ \\ ${ }^{1}$ Department of Neonatology, Maulana Azad Medical College, Delhi, India \\ ${ }^{2}$ Department of Paediatrics, MR Medical College, Gulbarga, Karnataka, India \\ ${ }^{3}$ Department of Paediatrics, Imperial College Healthcare NHS Trust, London, UK
}

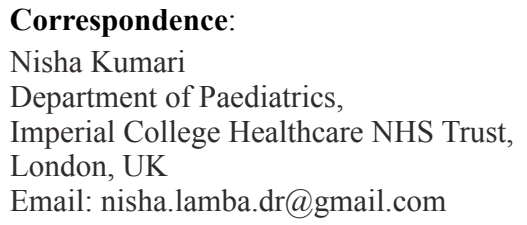

Correspondence:

Nisha Kumari

Department of Paediatrics,

Imperial College Healthcare NHS Trust,

London, UK

Email: nisha.lamba.dr@gmail.com

DOI: $10.3126 /$ jnps.v41i1.29993

Submitted on: 2020-07-11

Accepted on: 2021-02-12

Acknowledgements: None

Funding: Nil

Conflict of Interest: None declared

Permission from IRB: Yes
To cite this article: Jain A, Veerabhadrappa H, Shrikant SW, Kumari N.. Better Prediction of NeuroDevelopmental Outcome in Babies Using Combined Vojta's Neurokinesiological Examination, Amiel Tison Angles and Head Holding Grades. J Nepal Paediatr Soc. 2021;41(1):17-22.

\section{ABSTRACT}

Introduction: With the advances in medical technology, the survival rate has increased amongst the high-risk neonates. Changes occurring in the neuro-motor function during the first year of life are closely related to the maturation of the central nervous system of babies and the presence or absence of injury to brain. These should be detected as early as possible, so that intervention programmes can be started.

Methods: A prospective study was done in NICU of a teaching hospital, to find the predictive value of combined assessment by three neuro-developmental examinations Viz. Vojta's Neurokinesiological examination, Amiel-Tison angles and head holding grades. Total 375 babies with various high risk category were included, out of which only 114 infants completed one-year follow-up. On the first visit a detailed neurological examination was performed using Vojtas Neurokinesological postures, AmielTison angles and head holding grades based on Trivandrum Developmental Screening Chart (TDSC). At one year, the milestones attained were plotted against the BSID percentiles and babies assigned as developmentally delayed, if it was below $97 \%$ pass level. Sensitivity and specificity were calculated and propositions evaluated by chi-square test.

Results: $23 \%$ babies had developmental delay at one year. The important high risk factors were maternal risk factors 39\%, HIE with MAS, HIE stage-III, complications during NICU stay.

Conclusions: Vojta's Neurokinesiological examination is an effective screening test that can be applied to all high-risk neonates. The predictive value could be enhanced to $100 \%$, by using other simple tests, like Amiel-Tison Angles and Head holding grades by TDSC.

Key words: Amiel-Tison angles; High risk babies; Trivendrum developmental screening chart; Vojta's neurokinesiological

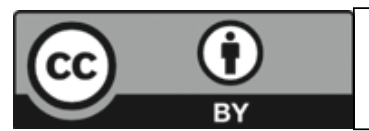

This work is licensed under creative common attribution 3.0 license 


\section{INTRODUCTION}

With the advances in medical technology and better neonatal intensive care, there has emerged an increased survival amongst the high risk neonates. Neuro-motor function changes during the first year of life are closely related to the maturation of the central nervous system of babies and the presence or absence of injury to brain. Therefore, it is important to keep a close watch on neurodevelopment of high risk babies, to detect abnormalities as early as possible, and to start intervention programmes at earliest.

Although neuro-imaging is often used to predict the neurological outcome, and in fact abnormal findings on MRI in preterm infants at termequivalent age can predict neuro-motor impairment at two years of age and also stratify infants by risk. ${ }^{1-3}$ Usage of MRI is limited in daily practice by its cost, accessibility and expertise requirement, especially in resource limited set ups. Cranial ultrasounds are routinely performed in some neonatal intensive care units, and there is a strong correlation which has been reported between severe lesions observed on neonatal cranial ultrasound and school-age MRI. ${ }^{2}$ Although, neonatal cranial ultrasound is highly reliable for the detection of intraventricular haemorrhage and cystic white matter injury, its ability to accurately diagnose noncystic lesions is limited. Therefore, the value of cranial ultrasound in predicting neurodevelopmental outcome in neonates remains controversial. $^{5-6}$ Hence, we need a clinical examination method for the neurological assessment to monitor baby's neuro-development.

This study was conducted to find the predictive value of combined assessment by three neurodevelopmental examinations viz. Vojta's Neurokinesiological examination ${ }^{7}$, Amiel-Tison ${ }^{8}$ angles and head holding grades.

\section{METHODS}

It was a prospective study done at Level - II NICU of a teaching hospital in India. The babies in NICU who had high risk of poor neuro - developmental outcomes were taken into the study. These included maternal risk factors like PPROM, fever, oligohydramnios, $\mathrm{BOH}, \mathrm{PIH}$, eclampsia, polyhydramnios, $\mathrm{Rh}$ incompatibility, MSAF and others. Informed verbal consent was taken from the parents before including the babies into the study. The study approval was taken from the Institutional Ethics Committee. Total 375 babies with various high risk categories were given high risk cards for follow-up. However, among the 375 babies, only 114 infants completed one year follow up from April 2019 to April 2020. The babies with congenital anomalies, very sick babies hindering examination and those who could not complete one year follow up were excluded from the study. High risk babies were given a special high risk card and asked to come at three, six, nine and 12 months of age regularly for follow up.

On the first visit i.e. three months, routine anthropometric measurements were taken, advice was given regarding diet, intercurrent illness were treated and a detailed neurological examination was performed using Vojtas Neurokinesological postures $^{9,10}$ viz. (1) Traction (2) Axillary hanging (3) Landau reaction (4) Lateral tilt (5) Collis horizontallis (6) Peiper isbert reaction (7) Collis vertical reaction.

The babies were also examined for five angles of Amiel-Tison ${ }^{11}$ viz (1) Heel to ear (2) Dorsiflexion angle (3) Popliteal angle (4) Scarf sign (5) Adductor angle and Head holding grades based on TDSC (Trivandrum Developmental Screening Chart). ${ }^{12}$

Each of reactions was read as normal or abnormal depending on postural signs observed and the motor handicap was graded as below.

- 1 - 3 abnormal: lightest central co-ordination disorder (CCD)

- 4 - 5 abnormal: light $\mathrm{CCD}$

- 6 - 7 abnormal: moderate CCD

- All reaction abnormal: Severe CCD

The grade of head holding less than two was taken abnormal and more than two as normal.

Similarly, more than three abnormal angles were taken as abnormal and less than three as normal. At one year, the number of milestones attained was plotted against the BSID ${ }^{13}$ - Baroda percentiles and the case was assigned delayed developmentally if it fell below the $97 \%$ pass level. The sensitivity and specificity of these tests were calculated and 
Table 1. Outcome of HIE Cases in the study

\begin{tabular}{|lrrr|}
\hline HIE stage & $\begin{array}{c}\text { Total No. } \\
\text { of cases }\end{array}$ & $\begin{array}{c}\text { Cases with } \\
\text { delay }\end{array}$ & Percentage \\
\hline Stage I & 35 & 2 & $5 \%$ \\
Stage II & 23 & 12 & $52 \%$ \\
Stage III & 8 & 7 & $87 \%$ \\
Total & 66 & 11 & $100 \%$ \\
\hline
\end{tabular}

propositions evaluated by chi-square test. P-value of $<0.05$ was taken as significant.

\section{RESULTS}

Total 114 babies had a neurological assessment at three, six, nine and 12 months. Seventy babies (61\%) were males and 44 babies $(39 \%)$ were females. $31 \%$ of babies (35 babies) had birth weight $<2.5 \mathrm{~kg}$ and $10 \%$ (12 babies) had weight $<$ $1.5 \mathrm{~kg}$. Prematurity was seen in $31 \%$ of babies and three babies $(3 \%)$ were post-term. As the hospital was a referral centre, $76 \%$ of babies (87) were hospital deliveries and $72 \%$ ( 82 babies) were delivered by NVD. Consanguinity was seen in 13 babies (11\%).

Maternal risk factors were present in 44 babies (39\%), which were PROM (11 - 44\%), fever (3 $6 \%)$, Oligohydramnios $(2-4 \%)$, BOH $(1-2 \%)$, PIH $(12-27 \%)$, Eclampsia $(3-6 \%)$, Polyhydramnios $(1-2 \%)$, Rh (2-4\%), MSAF (6$18 \%)$, others $(3-6 \%)$. Out of these 44 babies, 10 babies i.e. $39 \%$ went for developmental delay. The major risk factors associated with developmental delay were premature rupture of membrane (PROM) in $40 \%$, PIH and $\mathrm{BOH}$ in $20 \%$. One case had history of two abortions and two early neonatal deaths.

Table 3. Amiel Tison angles at three months and developmental outcome at one year

\begin{tabular}{|lrr|}
$\begin{array}{l}\text { Angles } \\
\text { Abnormal }\end{array}$ & $\begin{array}{c}\text { Developmentally } \\
\text { Abnormal }\end{array}$ & Normal \\
\hline More than three & 19 & 2 \\
Less than three & 7 & 86 \\
\hline
\end{tabular}

Trend Chi-square 22.7; $p<0.001$
Table 2. Vojta's Postures at three months and developmental outcome at one year

\begin{tabular}{|lrr|}
\hline $\begin{array}{l}\text { Reactions } \\
\text { abnormal }\end{array}$ & $\begin{array}{l}\text { Developmentally } \\
\text { Abnormal }\end{array}$ & \multicolumn{2}{c|}{ Normal } \\
\hline More than four & 26 & 4 \\
Less than four & 0 & 58 \\
\hline Trend Chi-square 9.36; $p<0.001$ & & \\
\hline
\end{tabular}

Various complications were studied in developmentally delayed babies, during their hospital stay. Almost all cases required oxygen and had feeding problems. Among the babies, $88 \%$ of cases had received inotorpic support with dopamine. Significant jaundice was noted in $69 \%$ of the cases and $46 \%$ developed septicaemia. About $15 \%$ of the cases had respiratory distress syndrome. The outcome in terms of development in the various HIE groups is depicted in Table 1.

In the study, $5 \%$ of stage $1 \mathrm{HIE}$ cases and $57 \%$ of stage II HIE and $87 \%$ of stage III HIE had developmental delay at one year of age. All cases of stage III HIE except one had more than six abnormal postures at three months examination. Only $26 \%$ of the stage II HIE cases and $2 \%$ of the stage I HIE cases had more than six postures abnormal at three-month examination. Table 2, Table 3 and Table 4 depicts the results of threemonth examination and neurodevelopment outcome at one year for the various tests.

The analysis of three simple tests used, was done in terms of negative predictive value (NPV), positive predicative value (PPV), specificity, sensitivity, false positive value, false negative value, $\mathrm{P}$ value, and accuracy was done. Table 5 depicts the results

Table 4. Head Holding Grades at three months and developmental outcome at one year

\begin{tabular}{|lrr|}
\hline Head Holding & Abnormal & \multicolumn{1}{c|}{ Normal } \\
\hline $\begin{array}{l}\text { More than grade } \\
\text { two }\end{array}$ & 12 & 0 \\
$\begin{array}{l}\text { Less than grade } \\
\text { two }\end{array}$ & 14 & 88 \\
\hline \begin{tabular}{l} 
Trend Chi.square 19.5: $p<0.001$ \\
\hline
\end{tabular} & & \\
\hline
\end{tabular}

Trend Chi.square 19.5; $p<0.001$ 
Table 5. Comparison of Statistical Parameters of the Three Examinations

\begin{tabular}{|llrrr|}
\hline SN & $\begin{array}{l}\text { Statistical } \\
\text { Parameter }\end{array}$ & Vojta's & Angles & $\begin{array}{c}\text { Head } \\
\text { Holding }\end{array}$ \\
\hline 1 & NPV & $86 \%$ & $90 \%$ & $46 \%$ \\
2 & PPV & $100 \%$ & $73 \%$ & $100 \%$ \\
3 & Specificity & $93 \%$ & $97 \%$ & $100 \%$ \\
4 & Sensitivity & $100 \%$ & $73 \%$ & $46 \%$ \\
5 & False positive & $6 \%$ & $2 \%$ & Nil \\
6 & False negative & Nil & $26 \%$ & 53 \\
7 & P value & 0.001 & 0.001 & 0.001 \\
8 & Accuracy & $95 \%$ & $92 \%$ & $87 \%$ \\
\hline
\end{tabular}

of various statistical parameters of the three examinations.

Thus from above tables, we could see clearly that all the tests individually have some statistical deficiencies, but when all the three tests are combined we attain a negative predictive value, positive predictive value, specificity, sensitivity of $100 \%$ and a nil false positive rate and false negative rate.

On calculation of relative risk and odd's ratios, HIE 3 had relative risk of 5.11 and odd's ratio of 32, topping the list followed by HIE with MAS with relative risk of 1.17 and odd's ratio of 8.7. Therefore, in our study HIE stage III had 32 times risk of having developmental delay and HIE 1 and 2 with MAS had eight times chances of having developmental delay.

\section{DISCUSSION}

Increased survival of many high risk babies presents as a formidable challenge to health professionals because of the fact that these babies carry high risk of developing neurological abnormalities, and therefore follow-up of these babies is very crucial. Early diagnosis and commencing appropriate therapy to address even the small deviation from the normal neurology leads to better long-term neuro-developmental outcome in babies. Therefore, it is of utmost importance to closely monitor the neurological development of babies esp. high risk babies with appropriate examination tools which have good predictive value.

The present study included a variety of high-risk babies as compared to earlier studies conducted by Choudhary et al., ${ }^{14,15}$ which included five high risk groups viz. HIE, preterm, IUGR, jaundice, septicaemia. Maiya PP et al. ${ }^{16}$ studied prediction of neuro-developmental outcome only in HIE babies, out of which $3.6 \%$ of the infants had HIE II and $77 \%$ had HIE III. Paro-Panjan et al. ${ }^{8}$ studied neurodevelopmental outcome in HIE, MAS, septicaemia, genetic syndromes.

We found that final developmental outcome was delayed in 26 babies out of 114 (23\%) compared to $39 \%$ in Maiya PP et al. ${ }^{10}$ and $11 \%$ in Choudhary et al. ${ }^{9}$ None of the patients in Maiya PP et al. ${ }^{16}$ study had abnormal reactions at three months who turned out to be normal, thus having a nil false positive rate and $100 \%$ negative predictive value. In our study four babies who were normal at one year had more than four postures abnormal bringing down the negative predictive value of $83 \%$ and a false positive rate of $6 \%$. Accordingly, the specificity of the test in our study was $93 \%$ compared to $100 \%$ in the study done by Maiya PP et al. ${ }^{16}$ study. Other characteristics of the tests like positive predictive value, $p$ value, sensitivity were similar in both the studies.

Using Amiel Tison neurological angles Choudhary et al., ${ }^{17}$ had a better negative predictive value of $96.9 \%$ compared to our study where it was $73 \%$. Leroux BG et al. ${ }^{18}$ studied using Amiel Tison neurological assessment to predict neurological outcome at two years in preterm babies, they concluded that Amiel Tison has a sensitivity and specificity of 0.55 (95\% CI 0.47 to 0.62 ), 0.65 (95\% CI 0.62 to 0.67 ), respectively. They also found out that abnormal neurological assessment at term was significantly associated with suboptimal neurological outcome at two years, with a specificity of 0.70 ( 0.67 to 0.71$)$, a sensitivity of 0.48 ( 0.41 to 0.56$)$, a positive likelihood ratio of 1.59 (1.34 to 1.89 ) and a negative likelihood ratio of 0.74 (0.64 to 0.86$)$.

Gajewska et al., ${ }^{19}$ studied neurodevelopmental outcome in very low birth weight babies and concluded that Vojta's diagnostic method is very sensitive in detecting injury of the central nervous 
system early in life and high correlation was found between cerebral palsy and asymmetry of the body, but not of the head. Imamura $\mathrm{S}$ et $\mathrm{al}^{20} \mathrm{did}$ a followup study where babies with motor development delay were classified as very light, light, moderate and severe Cerebral Coordination Disturbance (CCD) according to Vojta and they concluded that the severity of CCD correlates well with the neurodevelopmental prognosis.

In the present study, we attempted to combine three simple neurological examinations at three months and boost up the predictive value. On statistical analysis this was proved that combining the three tests a specificity, sensitivity, of $100 \%$ with nil false positive and negative rates and negative predictive value and positive predictive value of $100 \%$ can be obtained with accuracy close to hundred. Such screening tests are the valuable tools that tell the paediatricians and the parents to be vigilant about child's development and help for early introduction of intervention. This modality can help reduce the future disability and perhaps help the compromised babies a chance of fully functional future life. Limitations of our study are that ours is a single centre study with relatively less number of babies and relatively shorter period of follow up; therefore, this combination of tests needs further evaluations in multi-centre, larger study population with longer follow up.

\section{CONCLUSIONS}

The Vojta's Neurokinesiological examination is a very effective screening test with a sensitivity of $100 \%$ and a positive predictive value of $100 \%$. The results can be further enhanced by using other simple tests, like Amiel Tison Angles and Head holding grades by TDSC.

\section{REFERENCES}

1. Msall ME, Limperopoulos C, Park JJ. Neuroimaging and cerebral palsy in children. Minerva Pediatr 2009;61:41524. PMID: 19752850

2. Rademaker KJ, Uiterwaal CS, Beek FJ, Haastert IC, Lieftink AF, Groenendaal F, et al. Neonatal cranial ultrasound versus MRI and neurodevelopmental outcome at school age in children born preterm. Arch Dis Child Fetal Neonatal Ed. 2005;90:489-93. DOI: 10.1136/adc.2005.073908

3. Woodward LJ, Anderson PJ, Austin NC, Howard K, Inder TE. Neonatal MRI to predict neurodevelopmental outcomes in preterm infants. N Engl J Med. 2006;355:685-94. DOI: 10.1056/NEJMoa053792

4. Inder TE, Anderson NJ, Spencer C, Wells C, Volpe JJ. White matter injury in the premature infant: a comparison between serial cranial sonographic and MR findings at term. Am J Neuroradiol. 2003;24:805-9. PMID: 12748075

5. De vries LS, Van Haastert IC, Benders MJ, Groenendaal F. Myth: cerebral palsy cannot be predicted by neonatal brain imaging. Semin Fetal Neonatal Me. 2011;16:279-87. DOI: 10.1016/j.siny.2011.04.004

6. De Vries LS, Van Haastert IL, Rademaker KJ, Koopman C, Groenendaal F. Ultrasound abnormalities preceding cerebral palsy in high-risk preterm infants. J Pediatr. 2004;144:815-20. DOI: 10.1016/j.jpeds.2004.03.034

7. Sadowska L. Vaclav Vojta's neurokinesiological concept for the diagnosis and therapy of children with disturbances of motor development.Ortop Traumatol Rehabil. 2001;3(4):519-26. PMID:17984908

8. Paro-Panjan D, Neubauer D, Kodric J, Bratanic B. Amiel-Tison Neurological Assessment at term age: clinical application, correlation with other methods, and outcome at 12 to 15 months. Dev Med Child Neurol. 2005 Jan; 47(1):19-26. DOI: 10.1017/s0012162205000046.

9. Banaszek G. Vojta's method as the early neurodevelopmental diagnosis and therapy concept. Przeglad Lekarski. 2010;67(1):67-76. PMID: 20509579

10. Costi GC, Radice C, Raggi A, Kron AM, Angrisano A, Busato E, et al. Vojta's seven postural reactions in the detection of neuromotor disorders in infants. Pediatr Med Chir. 1983 Mar-Apr;5(1-2):59-65. PMID: 6634444.

11. Gosselin J, Gahagan S, Amiel-Tison C. The Amiel-Tison Neurological Assessment at Term: conceptual and methodological continuity in the course of follow-up. Ment Retard Dev Disabil Res Rev. 2005;11(1):34-51. DOI: https://doi.org/10.1002/mrdd.20049. 
12. Nair MK, George B, Philip E, Lekshmi MA, Haran JC, Sathy N. Trivendrum developmental screening chart. Indian Pediatr. 1991;869-71. PMID: 1725519.

13. Pathak AT, Khurana B. Baroda Developmental screening test for infants. Indian Pediatr. 1991;28:31-6. PMID: 1711514.

14. Chaudhari S, Kulkarni S, Pajnigar F, Pandit AN. A longitudinal followup of development of Preterm Infants. Indian Pediatr. 1991 Aug;873-80. PMID: 1808074.

15. Chaudhari S, Kulkarni S, Pandit A, Koundinya UK. Neurological assessment at three months as a predictor for developmental outcome in high risk infants. Indian Pediatr. 1993;30:528-31. PMID: 7507095.

16. Samatha S, Maiya PP. Predicting Neuro-Developmental Outcome at 3 months of age in babies with Hypoxic Ischemic Encephalopathy by Vojta's Neurokinesiological examination. Indian Pediatr. 1999;171-3. PMID: 10713811.

17. Chaudhari S, Shinde SV, Barve SS, Dixit HS, Pandit A. A longitudinal followup of Neuro-development of high risk new born - A comparison of Amiel Tison method with Bayley scales of Infant development. Indian Pediatr. 1990 Aug;799-802. PMID: 1703991.

18. Leroux BG, The Tich SNG, Branger B, Gascoin G, Rouger V, Berlie I, et al. Neurological assessment of preterm infants for predicting neuromotor status at 2 years: results from the LIFT cohort. BMJ Open. 2013;3:e002431. DOI: 10.1136/bmjopen-2012- 002431.

19. Gajewska E, Samborski W. Application of Vojta's method for early detection of developmental disturbances in very low birthweight infants with regard to Apgar score and asymmetric body positions. Ann Acad Med Stetin. 2006; 52:101-4. PMID: 17471844.

20. Imamura S, Sakuma K, Takahashi T. Follow-up study of children with cerebral coordination disturbance (CCD, Vojta). Brain Dev. 1983;5(3):311-14. DOI:10.1016/s0387-7604(83)80024-2. 